\section{Duodenal Perforation Secondary to Placement of a Biliary Endoprosthesis Diagnosed by Multislice Computed Tomography}

Duodenal perforation secondary to an endoscopically placed biliary endoprosthesis is a rare but potentially life-threatening complication [1-5]. We report the case of a patient with cholangiocarcinoma in whom a biliary plastic endoprosthesis was used for palliation.

A 53-year-old man underwent endoscopic retrograde cholangiopancreaticography (ERCP) due to progressive jaundice. After sphincterotomy a $15 \mathrm{~mm}$ long high-grade stenosis of the common bile duct - a finding indicating a likely cholangiocarcinoma - was treated by means of a $9 \mathrm{~cm}$, 7-F plastic endoprosthesis (Olympus, Tokyo, Japan). About $3 \mathrm{~cm}$ of the endoprosthesis remained in the duodenal lumen since the endoprosthesis could not be pushed more proximally.

The patient developed ERCP-related pancreatitis on the day of the ERCP. His symptoms improved during the following day, but 2 days later he complained of abdominal pain with rebound in the right lower quadrant. Physical examination disclosed signs of peritoneal irritation. A multislice computed tomography (CT) scan revealed a retroperitoneal perforation, with the distal tip of the endoprosthesis outside

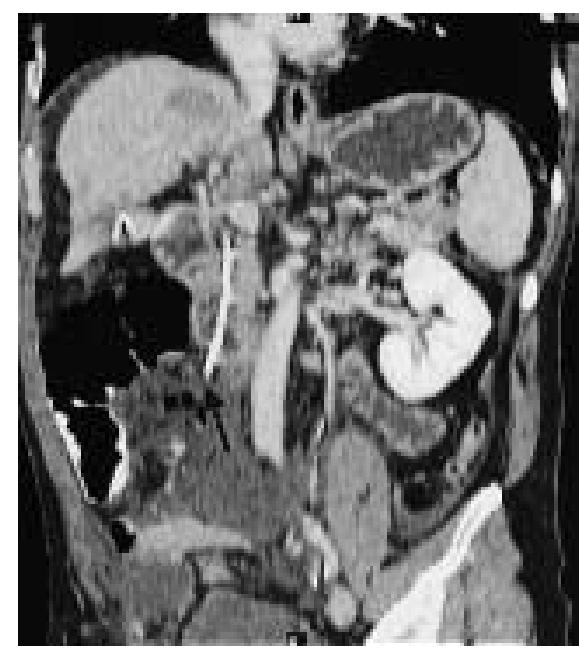

Figure 1 Multislice computed tomography scan in the coronal plane showing the tip of the endoprosthesis perforating the duodenal wall (arrow). Distally, free fluid and air can be seen the duodenum (Figure 1). The liver showed multiple inhomogeneous areas indicating liver metastases of the likely cholangiocarcinoma.

The perforation was confirmed (Figure 2 ), and secondary biliary peritonitis due to rupture of the ascending mesocolon was found at surgery. The endoprosthesis was replaced by nasobiliary drainage and the perforation was closed. Biopsies, which later revealed adenocarcinoma, were taken from metastases in the liver. The nasobiliary drain was replaced by a self-expanding metal endoprosthesis. The patient died 7 months later.

Duodenal perforation secondary to placement of a biliary endoprosthesis should be considered in all patients presenting with abdominal pain after such a placement. A multislice CT scan can provide an exact diagnosis of this complication. In the case of a localized process, the treatment of choice is endoscopic removal of the endoprosthesis $[2,3,5]$. Surgery should be reserved for patients with peritonitis, or extensive retroperitoneal phlegmon $[1,4]$.

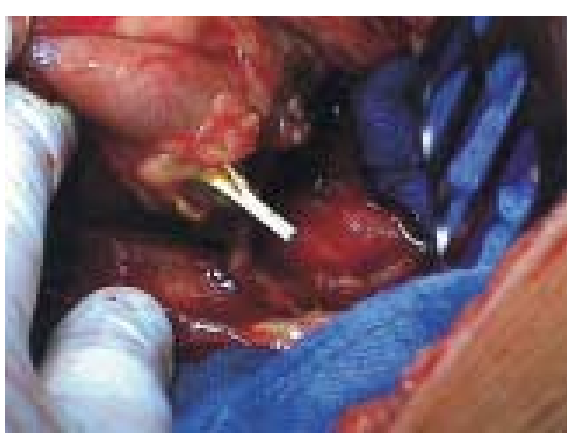

Figure 2 Operative view: the distal tip of the endoprosthesis has perforated the duodenum
G. Novacek ${ }^{1}$, M. Hörmann ${ }^{2}$, S. Puig ${ }^{2}$, F. Herbst ${ }^{3}$, A. Püspök ${ }^{1}$, R. Schöfl ${ }^{1}$

${ }^{1}$ Department of Internal Medicine IV, Division of Gastroenterology and Hepatology, University of Vienna, Vienna, Austria

${ }^{2}$ Department of Radiology, University of Vienna, Vienna, Austria

${ }^{3}$ Department of Surgery,

University of Vienna, Vienna, Austria

\section{References}

${ }^{1}$ Hauser H, Berger A, Brandstätter G. Duodenalperforation als Spätkomplikation nach endoskopisch retrograder Gallengangsendoprothesenimplantation. Wien Klin Wochenschr 1990; 192: $724-727$

2 Smith FCT, O'Connor HJ, Downing R. An endoscopic technique for stent recovery used after duodenal perforation by a biliary stent. Endoscopy 1991; 23: 244- 245

${ }^{3}$ Coppola R, Masetti R, Riccioni ME et al. Early retroduodenal perforation following endoscopic internal biliary drainage. Endoscopy 1993; 25: 255-256

${ }^{4}$ Humar A, Barron PT, Sekar ASC et al. Pancreatitis and duodenal perforation as complications of an endoscopically placed biliary stent. Gastrointest Endosc 1994; 40: 365 - 366

${ }^{5}$ Rosés LL, Ramirez AG, Seco AL et al. Clip closure of a duodenal perforation secondary to a biliary stent. Gastrointest Endosc 2000; 51: 487 - 489

\section{Corresponding Author}

\section{G. Novacek, M.D.}

General Hospital of Vienna Department of Internal Medicine IV Division of Gastroenterology and Hepatology

Waehringer Guertel 18 - 20 1090 Vienna

Austria

Fax: + 43-1-404004735

E-mail: Gottfried.Novacek@ akh-wien.ac.at 